\title{
Apresentação / Presentation
}

\section{Justiça e instituições sociais na democracia}

\section{Justice and social institutions in democracy}

$\mathrm{E}$

$m$ décadas recentes, a democracia ocupou um grande espaço tanto nas discussões acadêmicas como nos discursos políticos cotidianos. Governos democraticamente eleitos em muitos países latino-americanos, antes assolados por ditaduras militares, o fim dos regimes autoritários no leste europeu e, mais recentemente, a queda de ditadores em países do norte do continente africano e o ocaso de regimes autoritários em países como Burma/Myanmar e Hungria alimentaram esta presença. Enquanto ideólogos de plantão pretendiam estar detectando ondas de democracia, o final da história ou a irreversibilidade dos processos democráticos, a persistência de grandes desigualdades sociais, de estruturas econômicas, políticas, sociais e culturais percebidas como injustas por amplos setores da população e a frustração de esperanças de mudanças na vida cotidiana alimentaram descontentamentos, protestos ou desalentos. Como resultado, por baixo de uma fina cobertura de processos eleitorais regulares criaram-se oportunidades políticas para o crescimento de grupos e organizações que pouca importância dão à democracia.

A limitação da ideia de democracia fundamentalmente a processos de escolha de governantes através de eleições ocultou a continuidade persistente de instituições e formas de organização social não-democráticas nesses países. $\mathrm{Na}$ teoria social em geral, e na Ciência Política de forma particularmente mais acentuada, proliferam tendências, correntes e escolas de pensamento que restringem suas análises basicamente a formalismos procedimentais, deixando de lado evidências e indicadores que moderariam ou mesmo questionariam o otimismo com supostas mudanças. Pouca análise vem sendo feita sobre persistência ou mudança nas estruturas mais profundas da sociedade, nas relações cotidianas, nas possibilidades de eleger formas de vida, em suma: na democratização abrangente das relações sociais. A decisiva questão, se a sociedade está bem ordenada, se as instituições sociais são equitativas ou justas, ou se elas tornam efetivos os valores normativos da respectiva sociedade, tem sido insuficientemente analisada. As análises sociais resultantes têm sido incapazes de detectar os problemas substanciais da sociedade, de desvelar e 
verbalizar os princípios normativos assumidos nela e de subsidiar agentes sociais de transformações.

Esta inquietação nos tem motivado a propor e organizar a presente edição da Civitas em torno do tema da justiça e das instituições sociais. Em sintonia com a tese de Axel Honneth (2015; cf. Rosenfield e Saavedra, 2013; Sobottka, 2015), o objetivo foi acolher textos que incluíssem em seu escopo e nas análises a questão dos princípios de justiça social e dos valores que nossas sociedades, no transcurso de sua formação, assumiram para si como norteadores, criaram instituições sociais com o intuito de torná-los efetivos nas relações sociais cotidianas; textos que em sua estruturação não deixassem de lado a necessária conexão entre a análise da realidade e a formulação de juízos normativamente orientados por critérios imanentes, que caracteriza teorias sociais normativas de orientação crítica.

A edição reúne no núcleo temático oito textos e uma resenha, e se completa com três artigos avulsos. O texto de Axel Honneth, As enfermidades da sociedade: aproximação a um conceito quase impossível, abre a edição. Neste artigo Honneth busca um aclarar o conceito de enfermidade, entendido de maneira geral como uma desorganização específica das instituições sociais, afetando sua eficiência funcional. Mas quem estaria afetado pela enfermidade social: pessoas individuais em número significativo, o coletivo entendido como um macro-sujeito, ou é a "sociedade" em si? O autor parte das propostas teóricas de Alexander Mitscherlich e Sigmund Freud, mas vai além ao propor uma abordagem inserida cultural e historicamente: há enfermidade ou patologia social quando os arranjos institucionais de uma sociedade fracassam em relação às metas normativas que ela própria estabeleceu de acordo com os seus valores. Isso significa um descompasso entre modelos estabelecidos de socialização, seus valores e normas fundamentais, e os modos institucionalizados da produção, e estes, por sua vez, podem entrar em conflito com regulações normativas que articulam as relações de reconhecimento entre os membros da sociedade. Traçando um paralelo com Marx e Parsons, o autor reabilita a noção de função orgânica, constituindo um quadro de funcionalismo normativo. Consolida-se, assim, uma explicação mais em termos de funcionamento e organicidade, e a disfunção aparece como consequência de paradoxos normativos e institucionais que entram em conflito.

No texto Propriedade privada, crítica da reificação e a socialização dos meios de produção Hauke Brunkhorst articula a questão da desigualdade social simultaneamente no nível econômico e político. Condições desiguais e injustas de geração de riqueza econômica e de poder político são inerentes às sociedades estruturadas na propriedade privada dos meios de produção, que combinam a reificação de conceitos universais com interesses particulares de 
classe, normatizando-os. $\mathrm{O}$ argumento sustentado nesse artigo repousa sobre a viabilidade concreta - e não como uma utopia - da ideia do socialismo democrático, que interconecta a socialização dos meios de produção com a dominação política exercida pelos dominados. Dito diferentemente, os interesses das classes hoje internacionalmente dominantes não se constituem em um imperativo sistêmico. Em diversos países já está inclusive constitucionalizada a proteção da propriedade privada dos meios de produção como condicionada à efetividade de sua função social. Por conseguinte, na visão do autor não haveria mais obstáculos a "uma transição do estado de bem-estar tecnocrático para o socialismo democrático". Três décadas de dominação da episteme neoliberal, no entanto, tornaram mercados e investidores mundiais dominantes sobre as democracias, reduzindo constituições nacionais a direito simbólico. A recuperação do poder normativo do direito já constitucionalizado e do poder político dos dominados para influir na produção legislativa do direito, expressa na institucionalização de um socialismo democrático, é vista como desafio atual.

Louis Carré, em Beyond distribution: Honneth's ethical theory of justice, endossa a crítica ao paradigma distributivista proposta pela teoria honnethiana, baseado em três pressupostos: o procedimentalismo, o atomismo e o estadocentrismo. (1) A lógica procedimentalista das teorias da justiça, ao apontar que teorias normativas estão condenadas a considerar separadamente princípios de justiça construídos a priori e o leque de instituições sociais às quais esses princípios devem ser aplicados. (2) A lógica distributivista, supõe uma visão atomista das sociedades humanas nas quais as pessoas estariam apartadas das relações sociais e perderiam a condição de agentes morais. Honneth sustenta que a autonomia pessoal repousa na dimensão de reconhecimento mútuo, que pressupõe participação e cooperação. (3) O modelo de justiça distributivo traz consigo o estado-centrismo ao supor sempre alguma forma de centralização institucional capaz de articular e organizar a distribuição de bens de maneira equitativa. Em sua obra $O$ direito da liberdade, propõe-se a ultrapassar o hiato entre uma concepção normativa da justiça e a análise sociológica das sociedades modernas, ao propor a reconstrução normativa e colocar a ênfase na "liberdade social", baseada na dimensão intersubjetiva das "instituições de reconhecimento". A liberdade social prevê o acesso às instituições de reconhecimento. E aqui Carré esboça os problemas que são trazidos com esse avanço interpretativo. A análise do autor sugere que essas "instituições de reconhecimento" representariam um tipo de "bem primário" a ser igualmente distribuído entre os membros da sociedade, o que significaria um retorno ao paradigma distributivista. Como acessar de maneira equitativa as instituições de reconhecimento? E mais: e se essas instituições forem estruturalmente 
injustas? Eis ainda, pois, outro ponto problemático que repousa sobre a proposta de reconstrução do princípio normativo de justiça que guia as pessoas a participar das esferas de reconhecimento e cooperação, sem se colocar a questão se são intrínseca e estruturalmente justas. Como pensar a possibilidade de justiça ao participar dessas instituições?

Em Disrecognition, moral progress and second order disorders: on Axel Honneth's new theory of recognition Luiz Gustavo da Cunha de Souza faz uma crítica sobre a recente contribuição de Honneth em $O$ direito $d a$ liberdade para analisar realidades sociais distintas daquela que o autor tinha diante de si. Souza defende o argumento segundo o qual os diagnósticos sobre patologias e anomias seriam incapazes de descrever processos e contextos de "desreconhecimento" (Aberkennung). As "desordens de segunda ordem", entendidas como práticas sociais institucionalizadas que interpretam mal o real e suas normas, Honneth chama primeiramente de patologias do social e depois de anomia. O problema é que aos olhos de Honneth elas aparecem como disfunções que deveriam desaparecer ao longo do tempo, ao invés de vê-las como resultado de uma dinâmica política, negligenciando assim a análise da gramática moral dos conflitos sociais, alvo de sua atenção anteriormente, em seus escritos sobre a teoria do reconhecimento. O autor deste artigo advoga pela noção de "desreconhecimento" como forma de dar luz às tendências opostas ao progresso moral presentes na realidade, de forma a demonstrar a dinâmica política de contratendências morais, sem abandonar o quadro completo do reconhecimento. Cooperação e conflito, assim, seriam integrados à noção de reconhecimento e de justiça. No âmbito da reconstrução normativa, o descumprimento das normas é explicado ou como má interpretação (Fehldeutungen) do significado do direito à liberdade ou como desenvolvimento anormal (Fehlentwicklungen) das práticas de liberdade - chamados de patologias do social no primeiro caso, e de anomia no segundo. Enquanto as patologias representam a materialização das más interpretações, a anomia social se materializa nas próprias normas de reconhecimento. $\mathrm{O}$ problema, segundo Souza, repousa no descuido a respeito das origens da anomia no âmbito da dinâmica sócio-histórica. Seu argumento é que uma teoria da justiça não pode se satisfazer com uma análise das "desordens de segunda ordem" ou com o rumo inexorável da história, mas necessitaria buscar como ocorrem essas depurações. Pensar diferentemente da norma não é uma desordem mas objeto mesmo da investigação da teoria da justiça. Souza defende a noção de "desreconhecimento" para dar conta dos processos não contemplados pelas noções de patologia e anomia, diferenciando-se da noção de desrespeito, conforme Honneth usou anteriormente. Dessa maneira, o caminho proposto seria introduzir na teoria do reconhecimento a concepção 
do espaço político como lócus para exercer a criatividade, resolver conflitos e estabelecer normas de cooperação.

No artigo A justiça das instituições sociais: uma crítica da reconstrução normativa de $\mathrm{O}$ direito da liberdade de Axel Honneth Thiago Aguiar Simim oferece, em grandes linhas, uma reflexão sobre a passagem de Honneth, em $O$ direito da liberdade (2015), da teoria do reconhecimento (do jovem Hegel) para teoria da justiça como análise da sociedade (para o Hegel tardio). Nesta, trata-se de explorar, na pesquisa social como teoria normativa, a chamada transcendência na imanência. Ou seja, trata-se de se debruçar na realidade social para encontrar os princípios de justiça inscritos nas próprias práticas das instituições existentes e assim efetivá-los ainda mais. No entanto, para garantir o caráter crítico da reconstrução normativa, é preciso integrar também a dimensão tempo e com esse objetivo Honneth trabalha simultaneamente com as patologias sociais resultantes de uma certa interferência na efetivação própria da liberdade social, entendidas como falhas de socialização e não como interferências sistêmicas. Esse argumento garante o oferecimento, pelo autor, de um padrão normativo para a crítica. Assim, a articulação entre justiça e instituições sociais pressupõe igualmente a noção de reconhecimento recíproco em todos os âmbitos: na formação dos sujeitos, em suas relações sociais e na sua autorrelação prática. Simim argumenta, e expondo a revisão das esferas de reconhecimento entre Luta por reconhecimento e $O$ direito da liberdade, que as instituições de realização da liberdade social guardam em comum o reconhecimento como mecanismo fundamental da existência social. Nesse sentido, o reconhecimento foi cada vez mais se transformando em uma tese antropológica fundamental à experiência humana, realizada de formas distintas nas instituições sociais. A categoria de luta, oriunda do conflito moral, vai dando lugar à noção de reconciliação a ser concretizada na história em progresso. As noções de luta e conflito desaparecem de cena. Nesse artigo, Simim questiona, no entanto, se as formas saudáveis de realização da liberdade social ocorrem por pressões externas (e de luta) por democratização das instituições, ou se, ao contrário, se dão pelo desenvolvimento de um princípio interno, na forma de transcendência da imanência. Focandose especialmente na dimensão do mercado, o autor questiona o potencial libertador dessa dimensão ao colocar a difícil vinculação entre o funcionalismo presente no mercado de trabalho com a ideia de solidariedade, esta defendida como característica imanente dos mercados. As mudanças sociais ocorrem pelos princípios inscritos no próprio mercado ou por um controle externo que limita seu real mecanismo? Acredita que o sentido inicial de cooperação - pressuposto normativo do mercado - não se realiza por ele mesmo. Assim, segundo Simim, Honneth perderia tanto a possibilidade de um diagnóstico de 
tempo adequado à práxis real, como também o potencial crítico de sua análise. Admite, no entanto, que a reconstrução das instituições democráticas como uma das três esferas fundamentais da liberdade social é, sem dúvida, uma importante transformação na perspectiva de sua teoria, em especial a atenção dada, em $O$ direito à liberdade, à esfera pública democrática como um lócus de realização da liberdade social. Contudo, o autor conclui que haveria um ponto "cego" na teoria honnethiana quando esta sustenta que a transformação das instituições decorre da sua injustiça interna e se dá pela articulação política na esfera pública que retorna para a instituição social na forma de direitos. Demandas e pressões políticas teriam, ao contrário, importante papel nas transformações internas às instituições.

Em Reconstrução normativa em Axel Honneth e os múltiplos justos do mercado de trabalho as autoras Cinara Rosenfield, Luciana Garcia de Mello, Andressa S. Corrêa, analisam as contribuições de Axel Honneth para a ampliação de uma compreensão da justiça, fazendo uso da problematização proposta por este autor acerca das discrepâncias existentes entre os princípios normativos da justiça e a realidade social. Para superar essa lacuna, Honneth propõe construir uma teoria da justiça a partir dos requisitos das estruturas institucionais das sociedades modernas através do recurso metodológico da reconstrução normativa, que permitiria analisar o que é eticamente justo no social. A partir da análise do mercado de trabalho, tendo como base seus próprios estudos empíricos na área, as autoras exploram as potencialidades e limites deste recurso. Trata-se, concretamente, de compreender como a reconstrução normativa, no que tange ao conteúdo ético presente no mercado laboral, pode auxiliar a pensar o justo diante da multiplicidade atual de relações de trabalho - a chamada zona cinzenta do trabalho e emprego. A zona cinzenta é indicada neste artigo como um exemplo deste tensionamento entre um modelo de justiça normativo e o real encontrado na pesquisa social. A busca de formas alternativas de inserção laboral, fora dos cânones outrora institucionalizados da sociedade salarial, tem tomado um formato individualizado e atomizado. Se por um lado, constitui-se em alternativas individuais de autonomia, autenticidade e rompimento com a subordinação típica do trabalho assalariado, por outro, não é possível pensar essa busca como um projeto de liberdade social para todos. Assim, urge se colocar a questão: dado que o surgimento de novas relações de trabalho, tal como o autoempreendedorismo, são consideradas anomalias no modelo honnethiano (já que não conduzem à socialização do mercado e tampouco rementem a um contexto de cooperação), como encontrar hoje a medida do justo?

Partindo da teoria do reconhecimento, Emil A. Sobottka em seu texto Desrespeito e luta por reconhecimento questiona acerca da potencialidade 
da teoria de Axel Honneth, formulada em e com referência unicamente a sociedades economicamente centrais no capitalismo atual, como modelo para pesquisas em contextos distantes e distintos daquela sua origem. Nesse sentido, lança mão de pesquisa empírica realizada em contexto de periferia suburbana, feita com mulheres engajadas em uma política pública de segurança e cidadania, o programa Mulheres da Paz. Seu questionamento visa a responder acerca do potencial do sofrimento para desencadear - ou não - lutas por reconhecimento face a situações agudas de desrespeito. Estas situações são retratadas exemplarmente através de um extrato de uma destas narrativas. O autor prossegue em sua análise introduzindo os conceitos mobilizados por Honneth, de dessimbolização e a individualização institucionalizada. $\mathrm{O}$ primeiro conceito refere-se à falta de meios linguísticos e simbólicos para expressar a consciência de injustiça num marco mais amplo e articulado. O segundo tem a ver com as formas de organização da vida social que dificultam muito ou mesmo impedem uma partilha eticamente informada das experiências cotidianas de injúria e injustiça. Vencer essas duas barreiras seria uma condição necessária, mesmo que não suficiente em si. Sua pesquisa demonstrou que a capacidade de generalização que evidenciaria que essas práticas de desrespeito transcendem as relações individuais e estão enraizadas em hábitos ou estruturas muito mais amplas e profundas - e que necessitariam uma reação bem mais ampla que a indignação individual e silente -, se revelou ainda muito insipiente ou mesmo ausente nas pessoas entrevistadas. $\mathrm{O}$ autor conclui, por um lado, que nesta situação vivencial e política foi possível verificar que a teoria do reconhecimento pode sim ser operacionalizada e contribuir para as pesquisas empíricas em contextos bem distintos daquele que lhe serviu de referencial. Por outro lado, no entanto, a expectativa em Honneth de que o sofrimento e a percepção de ter sido injustiçado daria um impulso a iniciativas de superação desta situação, mostrou-se mais difícil e complexa. O autor constrói sua crítica a Honneth ao alegar que este parece ter esquecido as consequências que a dessimbolização e a individualização institucionalizada, por ele próprio descritas, têm como bloqueadoras de autorrelações práticas positivas. E sem elas, as dificuldades para protagonizar lutas por reconhecimento tornam-se muito grandes.

No artigo Inequality in contemporary Brazilian debate: between citizenship and recognition, Josué Pereira da Silva articula o problema da desigualdade no Brasil com a recepção às teorias de cidadania e reconhecimento. Para tal, mobiliza a teoria da desigualdade em Göran Therborn, a de cidadania em T. H. Marshall, a do reconhecimento em Charles Taylor, Axel Honneth e Nancy Fraser. Pelo lado brasileiro, e concluindo que o que unifica os autores brasileiros no tratamento ao tema da igualdade são as abordagens baseadas nas 
noções de cidadania e reconhecimento, traz à discussão os seguintes autores: José Murilo de Carvalho, Wanderley Guilherme dos Santos, Teresa Sales, Jessé Souza, Marcelo Neves, José Reinaldo de Lima Lopes. O autor sustenta que ambos os paradigmas, de cidadania e de reconhecimento, compartilham a preocupação com a questão da igualdade básica entre indivíduos em sociedade, mesmo diferindo nas suas abordagens. Para ambos a igualdade básica é condição para a autonomia e dignidade dos cidadãos das sociedades modernas, como forma de garantia de um sentimento de pertencimento a um todo solidário baseado em reciprocidade e não em assimetria. Se nos países europeus a crise do estado de bem-estar demanda um retorno à discussão da questão social com um novo compromisso capaz de prevenir a desintegração social e a exclusão, no Brasil as demandas são ainda mais prementes diante da desigualdade de recursos tanto materiais quanto simbólicos, que impedem de se aceder à busca por formas de igualdade vital e existencial. Assim, conforme apontado por pesquisas empíricas e teóricas, programas redistributivos poderiam certamente contribuir nesse sentido, ao diminuir a pobreza e a desigualdade e garantir condições básicas necessárias para deslanchar lutas contra as desigualdades vitais e existenciais.

O núcleo temático deste número da Civitas se encerra com a resenha que Luiz Gustavo da Cunha de Souza faz do livro Recognition, de Cillian McBride, no qual o autor relaciona o reconhecimento com práticas cotidianas do poder e da autoridade. Os textos Cidadania, reconhecimento e ação afirmativa no ensino superior, de Angela Randolpho Paiva, Cinco dimensiones del cosmopolitismo, de Daniel Loewe e A evolução democrática entre institucionalização e espontaneidade: pesos e medidas da política democrática contemporânea, de Leno Francisco Danner, completam a edição.

Desejamos a todos boa leitura!

Cinara L. Rosenfield Emil A. Sobottka

\section{Referências}

HONNETH, Axel. O direito da liberdade. São Paulo: Martins Fontes, 2015.

ROSENFIELD, Cinara L.; SAAVEDRA, Giovani A. Reconhecimento, teoria crítica e sociedade: sobre desenvolvimento da obra de Axel Honneth e os desafios da sua aplicação no Brasil. Sociologias, v. 15, n. 33, p. 14-54, $2013<10.1590 /$ S151745222013000200002>.

SOBOTTKA, Emil Albert. Reconhecimento: novas abordagens em teoria crítica. São Paulo: Annablume, 2015. 